\title{
A common African variant of human connexin 37 is associated with Caucasian primary ovarian insufficiency and has a deleterious effect in vitro
}

\author{
ANNE BACHELOT ${ }^{1,2^{*}}$, JEROME GILLERON ${ }^{3 *}$, GERI MEDURI $^{4}$, MIHELAI GUBERTO $^{5}$, JEROME DULON $^{1}$, \\ SYLVIANE BOUCHERIE $^{6}$, PHILIPPE TOURAINE ${ }^{1,2^{* *}}$ and MICHELINE MISRAHI ${ }^{\text {*** }}$ \\ ${ }^{1}$ AP-HP, Department of Endocrinology and Reproductive Medicine, Pitié-Salpêtrière Hospital, \\ Reference Center for Rare Endocrine Diseases of Growth, Reference Center for Rare Gynecological Pathologies; \\ ${ }^{2}$ University Pierre and Marie Curie, University Paris 6, F-75013 Paris; ${ }^{3}$ National Institute of Health and Medical Research \\ INSERM U1065 - University of Nice-Sophia Antipolis, Mediterranean Center for Molecular Medicine C3M, F-06000 Nice; \\ ${ }^{4}$ National Institute of Health and Medical Research INSERM U1195; ${ }^{5}$ University Paris-Sud, University Paris Saclay, \\ Medical Faculty Paris-Sud, Bicêtre Hospital, F-94275 Le Kremlin Bicêtre; ${ }^{6}$ National Institute of Health and \\ Medical Research UMR-S 757 INSERM, University Paris-Sud, F-91400 Orsay, France
}

Received July 11, 2017; Accepted October 20, 2017

DOI: $10.3892 /$ ijmm.2017.3257

\begin{abstract}
Folliculogenesis requires communication between granulosa cells and oocytes, mediated by connexin-based gap junctions. Connexin 37 (Cx37)-deficient female mice are infertile. The present study assessed $\mathrm{Cx} 37$ deficiency in patients with primary ovarian insufficiency (POI). A candidate gene study was performed in patients and controls from the National Genotyping Center (Evry, France) including 58 Caucasian patients with idiopathic isolated POI and 142 Caucasian controls. Direct genomic sequencing of the coding regions of the GJA4 gene (encoding Cx37) was performed with the aim to identify a deleterious variant associated with POI and absent in ethnically matched controls. A single Cx37 variant absent in the control population was identified, namely a c.946G $>A$ heterozygous substitution leading to a p.Gly316Ser variant that was present in two POI patients. This variant was absent in all Caucasian controls from various databases, and has been observed exclusively in African populations. This variant was
\end{abstract}

Correspondence to: Professor Philippe Touraine, AP-HP. Department of Endocrinology and Reproductive Medicine, PitiéSalpêtrière Hospital, Reference Center for Rare Endocrine Diseases of Growth, Reference Center for Rare Gynecological Pathologies, 47 Boulevard de l'Hôpital, F-75013 Paris, France

E-mail: philippe.touraine@aphp.fr

\section{${ }^{*, * * *}$ Contributed equally}

Key words: connexin 37, GJA4, candidate gene, variant, mutation, primary ovarian failure, African, Caucasian, Gap-fluorescence recovery after photobleaching, confocal microscopy identified to have a dominant negative effect in HeLa cells in vitro to alter connexon function (by $67.2 \pm 7.17 \%$ ), as determined by Gap-fluorescence recovery after photobleaching. The alteration principally resulted from a decrease of cell surface connexons due to altered trafficking (by 47.73 $\pm 8.59 \%$ ). In marked contrast to this observation, a p.Pro258Ser variant frequent in all ethnic populations in databases had no functional effect in vitro. In conclusion, the present study reported on a Cx37 variant in two Caucasian POI patients, which was absent in control Caucasian populations, and which had a deleterious effect in vitro. It is therefore suggested that in the genetic context of the Caucasian population, this variant may contribute to POI.

\section{Introduction}

Premature ovarian insufficiency (POI) is a disorder affecting $\sim 1 \%$ of women under the age of 40 years (1) and is caused by two major mechanisms, namely follicle dysfunction and follicle depletion (2), while the aetiology remains undetermined in most cases (3). In addition to complete loss-of-function mutations, partial molecular defects may be the underlying cause of unexpected partial phenotypes (4). Of note, certain women with POI experience an unpredictable resumption of ovarian function $(1,5)$, with $3-10 \%$ conceiving spontaneously after diagnosis $(3,5)$. Genetic causes of non-syndromic POI account for $10-15 \%$ of patients (2). Chromosomal abnormalities or rare gene defects have been described in association with POI $(2,6)$. In non-syndromic POI, among autosomal genes, only rare mutations of gonadotropin receptors or their ligands (7), of growth factors [bone morphogenetic protein (BMP15), growth differentiation factor 9) or transcription factors involved in follicular growth (splicing factor 1), of genes involved in the establishment of the follicular pool and initial recruitment (POF1B, folliculogenesis specific bHLH transcription factor, 
NOBOX), and recently in meiosis (cohesin: Stromal antigen 3) have been described $(4,6,8-12)$. This strongly suggests that additional genetic factors remain to be identified.

Gap junction intercellular communication (GJIC) has a key role in mammalian ovarian follicle development (13). Gap junctions are channel clusters formed by connexins, essential for oocyte-granulosa cell communications. In mice, connexin 37 (Cx37) invalidation results in ovarian folliculogenesis arrest at the preantral stage and female infertility $(14,15)$. Therefore, the present study assessed the involvement of Cx37 in POI.

\section{Subjects and methods}

Patients and controls. The review boards of the institutions involved approved this study and informed consent was obtained from all patients. A total of 58 patients with POI from a national cohort described in previous studies by our group were assessed $(3,5)$. These included 12 patients with primary and 46 with secondary amenorrhea (including 21 with resumptive ovarian function). A population of 142 Caucasian controls (from the Centre National de Genotypage) was also studied.

DNA sequencing of the GJA4 gene. DNA was extracted from the peripheral leukocytes of the patients. Automated direct genomic sequencing of the full coding region of the gene encoding Cx37 (GJA4) was performed. Two pairs of primers were used for polymerase chain reaction (PCR) to amplify the coding regions of GJA4: Forward (F)1, 5'-GGA CGG AGG CCG GGA GCC AT-3' and reverse (R)1, 5'-AGT GGC GCC TGT ACG GCT GG-3'; F2, 5'-GGC AGG CTT CCT CTA TGG CC-3' and R2, 5'-TCC TGA GAA GTC TGG CTG CCT GGG-3'.

PCR was performed using TaqDNA polymerase and PCR mixture (cat. no. 10342-020; Invitrogen; Thermo Fisher Scientific, Inc., Illkirch, France) under the following conditions: $94^{\circ} \mathrm{C}$ for $5 \mathrm{~min}, 30$ cycles of $94^{\circ} \mathrm{C}$ for $30 \mathrm{sec}, 62^{\circ} \mathrm{C}$ for $45 \mathrm{sec}, 72^{\circ} \mathrm{C}$ for $1 \mathrm{~min}$ and $60^{\circ} \mathrm{C}$ for $1 \mathrm{~min}$, followed by a final elongation for $8 \mathrm{~min}$ at $72^{\circ} \mathrm{C}$. A total of 10 primers were used for double-strand direct genomic sequencing of GJA4 F1, 5'-GGA CGG AGG CCG GGA GCC AT-3' and R1, 5'-GCA GAA GGA GGG GGA GCT-3'; F2, 5'-GAG CAG TCA GAT TTC GAG TG-3' and R2, 5'-AGT GGC GCC TGT ACG GCT GG-3'; F3, 5'-CCT GTC TCG GCG AGA AGA G-3' and R3, 5'-CTG CCT CAG CCG GGG GAT GA-3'; F4, 5'-GGC AGG CTT CCT CTA TGG CC-3' and R4, 5'-CAG AAC TGG GCC AAC CTG A-3'; F5, 5'-GCT GTG TCG CTG CCT CAG-3' and R5, 5'-TCC TGA GAA GTC TGG CTG CCT GGG-3'. Automated sequencing was performed with an ABI 310 Genetic Analyzer (Applied Biosystems; Thermo Fisher Scientific, Inc., Waltham, MA, USA).

The c.860C $>$ T heterozygous GJA4 mutation encoding Cx37 p.Pro258Ser and introducing a HinfI restriction site was also verified by restriction fragment length polymorphism analysis. The c.1034G $>$ A heterozygous GJA4 mutation encoding Cx37 p.Gly316Ser was verified in the control population by doublestrand direct sequencing.

Generation ofGFP-Cx37-wild-type(WT) and GFP-Cx37-mutant probes. Mutagenesis was assessed as follows: An OmicsLink ${ }^{\mathrm{TM}}$
Expression Clone [cytomegalovirus promoter; pReceiver-M29 (a,x,y) Expression Clone; GeneCopoeia, Rockville, MD, USA] encoding the wild-type Cx37 was applied. This vector encodes a fusion protein with green fluorescent protein (GFP) at its N-terminus. The QuikChange ${ }^{\circledR}$ II XL Site-Directed Mutagenesis kit (cat. no. 200521; Stratagene, Cedar Creek, TX, USA). Mutant constructs were engineered by oligonucleotide-mediated mutagenesis on this vector by PCR. The c.749C $>$ T (p.Pro258Ser) substitution was engineered with two mutagenic primers: F, 5'-GGCACCTCCTCAGACTCTTACACGGACCAGGTCT-3' and R, 5'-AGACCTGGTCCGTGTAAGAGTCTGAGGAGGT GCC-3', binding at positions 757 and 790 of the complementary cDNA sequence, respectively, with position +1 corresponding to the first nucleotide of the initiation codon (ATG). The mutated bases are underlined. The c.946G>A (p.Gly316Ser) mutation was engineered with two mutagenic primers: F, 5'-GACCCACCCCC TCAGAATAGCCAAAAACCCCCAAGTC-3' and R, 5'-CTTG GGGGTTTTTGGCTATTCTGAGGGGGTGGGTC-3', binding at positions 928 and 964 of the cDNA sequence, respectively, with position +1 corresponding to the first nucleotide of the initiation codon (ATG). The mutated bases are underlined. Mutants were verified by direct sequencing with the following primer, 5'-TTAACCTGCTGGAGTTGGTG-3'.

Chemicals and antibodies. Calcein-red AM was purchased from Invitrogen (Thermo Fisher Scientific, Inc., Illkirch, France), while rabbit anti-giantin (1:1,000 dilution; ab80864), rabbit anti-early endosome antigen 1 (EEA1; 1:1,000 dilution; ab2900) and mouse anti-lysosome-associated membrane protein 2 (LAMP2; 1:100 dilution; ab25631) (all from Abcam, Cambridge, UK) antibodies were purchased from Covance (Princeton, NJ, USA), Santa Cruz Biotechnology, Inc. (Dallas, TX, USA) and BD Pharmingen (San Jose, CA, USA), respectively, and goat anti-rabbit and anti-mouse secondary antibodies conjugated to Alexa Fluor 647 (cat. nos. 115-605-146 and 111-605-144) were obtained from Jackson ImmunoResearch (West Grove, PA, USA). GFP-Rab5 probe was a gift from M. Zerial Laboratory (Dresden, Germany).

Cell culture and transfection. HeLa cells (ATCC, Manassas, VA, USA) were used for functional studies, as they do not express functional connexins and gap junctions. They were cultured in Dulbecco's modified Eagle's medium (Invitrogen; Thermo Fisher Scientific, Inc.) supplemented with $10 \%$ fetal calf serum (Gibco, Waltham, MA, USA) and 1\% penicillin/streptomycin at $37^{\circ} \mathrm{C}$ in a humidified atmosphere containing $5 \% \mathrm{CO}_{2}$. The cells seeded into 96-well plates at a density of 15,000 cells/well and were transfected in the presence of Lipofectamine (Invitrogen; Thermo Fisher Scientific, Inc.) as previously described (16). For each milliliter of transfection mixture, $8 \mu 1$ Lipofectamine was mixed with $200 \mu \mathrm{l}$ OptiMem (Invitrogen; Thermo Fisher Scientific, Inc.) and simultaneously, $0.75 \mu \mathrm{g}$ of each GFP-Cx37 (WT and/or mutant) probe was mixed with $200 \mu$ l OptiMem in a separate vessel. The two mixtures were incubated at room temperature in the dark for $45 \mathrm{~min}$. The mixtures containing the probes were then individually added to those containing Lipofectamine. The combination was mixed smoothly and incubated for another $15 \mathrm{~min}$ at room temperature in the dark. A total of $600 \mu 1$ DMEM without serum was then added dropwise to each well. The transfection efficiency was 
assessed after $24 \mathrm{~h}$ by determining the proportion of total cells transfected by GFP fluorescence. No significant difference in transfection efficiency was observed between mutant and WT expression vectors used separately [Cx37-P258S (47.12 $\pm 1.65 \%)$

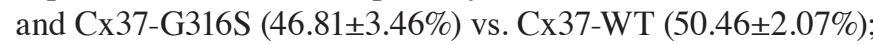
$\mathrm{P}=0.2771$ and 0.4180 , respectively, $\mathrm{n}=3$ ].

Immunofluorescence imaging and colocalization analysis. HeLa cells transfected for $24 \mathrm{~h}$ with expression vectors encoding WT green fluorescence protein (GFP)-Cx37-WT, or mutated GFP-Cx37-P258S or GFP-Cx37-G316S connexins, were fixed with $4 \%$ paraformaldehyde. The cells were permeabilized by incubation for $5 \mathrm{~min}$ in $0.1 \%$ saponin in phosphate-buffered saline (PBS), and then blocked by incubation in 3\% bovine serum albumin (Sigma-Aldrich, St. Louis, MO, USA) and $0.01 \%$ saponin in PBS for $30 \mathrm{~min}$ at room temperature. The cells were incubated at room temperature with primary antibodies in blocking solution for $2 \mathrm{~h}$, and then with secondary antibodies conjugated with Alexa Fluor 647 and 4',6-diamidino-2-phenylindole (DAPI) for the labeling of nuclei for $1 \mathrm{~h}$. Images were acquired with a Zeiss LSM512 confocal microscope (Zeiss AG, Jena, Germany). The number of colocalized objects (structures or vesicles positive for staining) was analyzed, as previously described (17), with ImageJ software (National Institutes of Health, Bethesda, MD, USA; release 1.48e 19 October 2013). For each image, a colocalization mask was first generated using the colocalization plugin for ImageJ software (Colocalization Highlighter; Pierre Bourdoncle, Institut Jacques Monod, Service Imagerie, Paris, France). The number of objects in each channel (green, red and colocalized) was then estimated with the particle counter of ImageJ software. Finally, the number of colocalized particles was determined by dividing the number of colocalized objects by the total number of particles.

Gap-fluorescence recovery after photobleaching (FRAP) analysis. HeLa cells, either untransfected or transfected with GFP-Cx37-WT, alone or together with GFP-Cx37-G316S or GFP-Cx37-P258S expression vectors for $24 \mathrm{~h}$, were loaded for $30 \mathrm{~min}$ at $37^{\circ} \mathrm{C}$ with $5 \mu \mathrm{M}$ calcein-red AM (Invitrogen; Thermo Fisher Scientific, Inc.) in PBS. Dye transfer was then monitored with a Zeiss LSM 510 confocal microscope, as previously described (18). Randomly selected cells were bleached with a 543-nm laser pulse and the recovery of fluorescence intensity was monitored by analyzing data obtained prior to bleaching, just after bleaching and $30 \mathrm{~min}$ after photobleaching using Zeiss LSM software (version 2.01). The percentage of fluorescence recovery was determined by normalizing all values to the intensities prior to photobleaching set as $100 \%$ and subtracting the normalized value for cells just after photobleaching from the normalized value obtained at $30 \mathrm{~min}$ after photobleaching. At least 20 cells were analyzed for each set of experimental conditions and at least three separate experiments were performed.

Statistical analysis. Values are expressed as the mean \pm standard error of the mean. Student's t-test or analysis of variance followed by Bonferroni's post hoc comparison was used for statistical analysis (GraphPad, Prism, version 5.03). $\mathrm{P}<0.05$ was considered to indicate a statistically significant difference.

\section{Results}

A common African variant of human Cx37 may be associated with Caucasian primary ovarian insufficiency. Direct genomic sequencing of the GJA4 coding region in 58 POI patients identified a single specific variant in two Caucasian patients, which was absent in the ethnically matched Caucasian controls. An identical heterozygous substitution [c.946 G>A, (NM_002060)] in these two patients led to the production of a p.Gly316Ser (G316S) Cx37 mutant protein (Fig. 1A).

The affected residue, at the $\mathrm{Cx} 37 \mathrm{COOH}$-terminus (Fig. 1B), is highly conserved across species (Fig. 1C). Various databases [National Center for Biotechnology Information, Ensembl, 1000 Genomes (1000G), exome variant server (ESV)] were searched for the variants identified in the present study. The rs140949366 variant corresponding to c.946G $>$ A encoding p.G316S was neither detected in European, non-African North or South American, Caribbean Puerto Rican and Asian populations according to the $1000 \mathrm{G}$ database $(0 / 1,688$ chromosomes) nor detected in European Americans according to the ESV database (0/8,600 chromosomes). However, the rs140949366 variant was included in the $1000 \mathrm{G}$ and ESV databases, but exclusively occurred in African populations. It was detected 12 times in a sample population of 1,088 individuals (or 2,176 chromosomes) from populations of African origin from Nigeria, Kenya, Gambia and African Americans according to the $1,000 \mathrm{G}$ database. This variant was also listed in the ESV database exclusively in African Americans in a sample population of 12,885 chromosomes (121/4285). In the Exome Aggregation Consortium (ExAC) database, this variant was listed only 9 times in 72,500 Caucasian chromosomes, but no information was available regarding the gender and phenotype of the relevant individuals and the pathogenicity of the variant.

Two Pro258Ser and Pro319Ser polymorphisms (rs28739284 and rs1764391) present in the POI patients were also identified to be present in all ethnic populations of different databases and also in the control population of the present study.

In conclusion, an association between a Cx37 variant, which was absent in ethnically matched Caucasian populations, but present in 2 Caucasian patients with POI was identified. This variant is highly conserved across species, suggesting a possible functional role.

\section{Case presentations}

The two patients with a CX37 mutation identified are described below. Case 1. The first patient was a 25-year-old Caucasian woman who was referred to the Department of Endocrinology and Reproductive Medicine, Pitie Salpetriere Hospital (Paris, France) for secondary amenorrhea and primary infertility. She had a normal pubertal development and regular menstrual cycles since the age of 11 . She displayed secondary amenorrhea and experienced hot flushes at the age of 23 years. No hormonal evaluation had been performed at this age. Various sequential progestin tests resulted in vaginal bleeding between the ages of 23 and 25 years. At the age of 25 years, the patient underwent hormonal and ultrasound evaluations at the same department leading to the diagnosis of POI (Table I). Androgen levels [testosterone, androstenedione and dehydroepiandrosterone sulfate (DHEA-S)] were within normal ranges. Metabolic evaluation (glycaemia, cholesterol and triglyceride levels) had no 
Table I. Clinical, hormonal and US characterisation of patients with connexin 37 mutation.

\begin{tabular}{|c|c|c|c|c|c|c|c|c|c|c|c|c|c|}
\hline Case & $\begin{array}{c}\text { Type of } \\
\text { amenorrhea } \\
\text { (age at onset) }\end{array}$ & $\begin{array}{c}\text { Age at } \\
\text { evaluation } \\
\text { (years) }\end{array}$ & $\begin{array}{c}\text { Day of the } \\
\text { menstrual } \\
\text { cycle }\end{array}$ & $\begin{array}{c}\text { FSH } \\
\mathrm{UI} / 1\end{array}$ & $\begin{array}{l}\mathrm{LH} \\
\mathrm{UI} / 1\end{array}$ & $\begin{array}{c}\mathrm{E}_{2} \\
\mathrm{pg} / \mathrm{ml}\end{array}$ & $\begin{array}{c}\text { Inhibin B } \\
\mathrm{pg} / \mathrm{ml}\end{array}$ & $\begin{array}{l}\mathrm{AMH} \\
\mathrm{ng} / \mathrm{ml}\end{array}$ & $\begin{array}{c}\mathrm{T} \\
\mathrm{ng} / \mathrm{ml}\end{array}$ & $\begin{array}{c}\mathrm{P} \\
\mathrm{ng} / \mathrm{ml}\end{array}$ & $\begin{array}{c}\text { Ovarian } \\
\text { surface } \\
\text { (right/left) } \\
\mathrm{cm}^{2}\end{array}$ & $\begin{array}{l}\text { Presence of } \\
\text { follicles at US } \\
\text { (size of the } \\
\text { largest, mm) }\end{array}$ & $\begin{array}{c}\text { Resumption } \\
\text { of ovarian } \\
\text { function }\end{array}$ \\
\hline \multirow[t]{3}{*}{ Patient 1} & $\begin{array}{l}\text { Secondary } \\
\text { (23 years) }\end{array}$ & 25 & Amenorrhea & 40 & 10.8 & 20 & 15 & $<0.05$ & 0.3 & 0.3 & $3.4 / 5.9$ & Yes (14) & $\begin{array}{c}\text { Yes } \\
\text { (resumption of } \\
\text { menstrual cycles) }\end{array}$ \\
\hline & & 28 & 3 & 109 & 51 & 46 & ND & ND & ND & 0.4 & ND & Yes (8) & \\
\hline & & 28 & 8 & 106 & 51 & 43 & ND & ND & ND & 0.4 & ND & ND & \\
\hline Patient 2 & $\begin{array}{l}\text { Secondary } \\
\text { ( } 25 \text { years) }\end{array}$ & 31 & Amenorrhea & 73 & 36 & $<10$ & $<10$ & $<0.05$ & 0.2 & ND & ND & No & No \\
\hline
\end{tabular}

US, ultrasonography; $\mathrm{E}_{2}$, estradiol; T, testosterone; $\mathrm{P}$, progesterone; $\mathrm{NA}$, not available; $\mathrm{ND}$, not determined; $\mathrm{FSH}$, follicle-stimulating hormone; $\mathrm{LH}$, luteinizing hormone; $\mathrm{AMH}$, anti-mullerian hormone.

Normal baseline values

\begin{tabular}{lcccccc}
\hline Phase & FSH $(\mathrm{U} / \mathrm{l})$ & $\mathrm{LH}(\mathrm{UI} / \mathrm{l})$ & $\mathrm{E}_{2}(\mathrm{pg} / \mathrm{ml})$ & $\mathrm{T}(\mathrm{ng} / \mathrm{ml})$ & $\mathrm{P}(\mathrm{ng} / \mathrm{ml})$ & $\mathrm{Inhibin} \mathrm{B}(\mathrm{pg} / \mathrm{ml})$ \\
\hline Follicular & $3.5-12$ & $1.5-8$ & $20-85$ & $0.1-0.48$ & $0.2-1.5$ & $10-276$ \\
Ovulatory & $4.7-21.5$ & $9.6-80$ & $82-287$ & $0.1-0.48$ & $0.8-3.0$ & $1.7-27.0$ \\
Luteal & $1.7-7.7$ & $0.2-6.5$ & $8-33$ & $0.1-0.48$ & $0.1-0.8$ & $<10$ \\
Menopause & $26-135$ & $8-33$ & $<35$ & $0.1-0.4$ & 0 \\
\hline
\end{tabular}

In women with a normal menstrual cycle, the normal range of anti-mullerian hormone is 2.2-6.8 ng/ml. $\mathrm{E}_{2}$, estradiol; T, testosterone; $\mathrm{P}$, progesterone; FSH, folliclestimulating hormone; LH, luteinizing hormone.

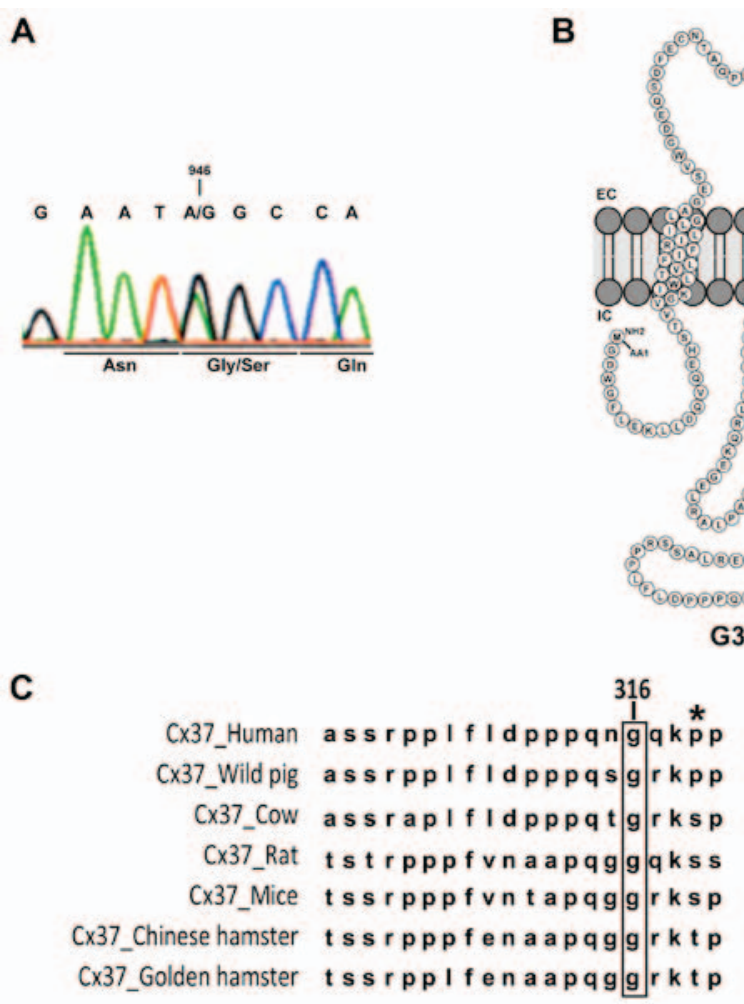

Figure 1. Gly316Ser mutation in human Cx37 identified in two patients with POI. (A) Direct genomic sequencing of GJA4 for one POI patient with the c. $946 \mathrm{G}>\mathrm{A}$ variant. The changed base and the corresponding codon are indicated. (B) Schematic representation of Cx37 and localization of the G316S residue in the C-terminal part of the intracellular domain. (C) Alignment of Cx37 sequences in different species (human, Homo sapiens; wild pig, Sus scrofa; cow, Bos taurus; rat, Rattus norvegicus; mouse, Mus musculus; Chinese hamster, Cricetulus griseus; golden hamster, Mesocricetus auratus). The high level of conservation of the glycine 316 residue (in brackets) was apparent among the species. The asterisk indicates the well-described P319S polymorphism of Cx37 present in all populations studied in databases (note that this residue has not been conserved during evolution). Cx, connexin; POI, primary ovarian insufficiency; EC/IC, extra/intracellular space. 


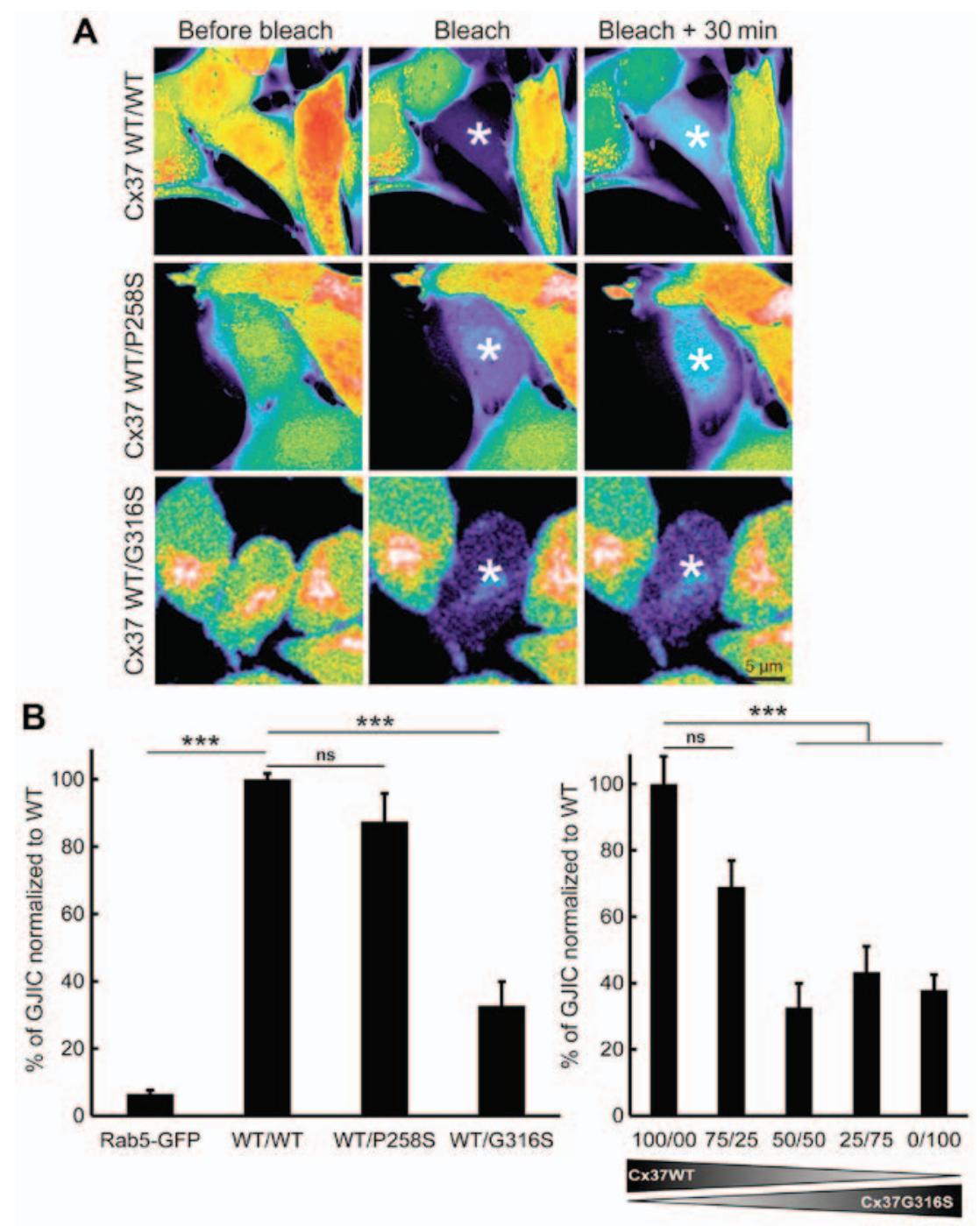

Figure 2. The Cx37-G316S variant exerts a partial dominant negative effect on WT Cx37. (A) Representative images of gap junction intercellular communication functional assays based on fluorescence recovery after photobleaching (Gap-FRAP images are presented with a pseudocolor gradient to facilitate the detection of variants). The asterisks indicate the photobleached cells (scale bar, $5 \mu \mathrm{m}$ ). (B) Quantitative analyses of the Gap-FRAP studies. The graph on the left indicates a strong, but incomplete dominant negative effect of the G316S variant on the WT allele and the lack of a dominant negative effect of the P258S variant. The graph on the right indicates that the dominant negative effect of $\mathrm{Cx} 37-\mathrm{G} 316 \mathrm{~S}$ is dose-dependent. ${ }^{* * *} \mathrm{P}<0.01$. Cx, connexin; FRAP, fluorescence recovery after photobleaching; WT, wild-type; ns, not significant; GFP, green fluorescence protein; GJIC, Gap junction intercellular communication.

abnormalities. Ovarian ultrasonography indicated the presence of a 34x20-mm cyst and two 5-mm follicles on the left ovary and of a normal-sized 30x14-mm right ovary with a 5-mm follicle. The menstrual cycle resumed spontaneously at 2 months after this evaluation, lasting 28 to 40 days. The patient revisited the center at the age of 28 . She continued to have regular menstrual cycles of 40 days and considered pregnancy at this time. The patient's mother had 6 spontaneous pregnancies between the ages of 24 and 30 years, resulting in 3 spontaneous abortions and 3 children, two of which were male and had no reported fertility problems and case 1 of the present study. The patient's mother presented with premature ovarian failure at the age of 38 years and was unavailable for further analysis.

Case 2. The second patient was a 31-year-old Caucasian woman born to consanguineous parents with congenital familial deafness of unknown aetiology. Her brother also suffered from deafness. She had a normal puberty and menses from the age of 13 onward. The diagnosis of premature ovarian insufficiency was performed when she was 25 and had developed secondary amenorrhea (Table I). At the age of 31 (October, 2007), hormonal measurements revealed the following: Folliclestimulatory hormone (FSH) N:3.5-12), $73 \mathrm{UI} / 1$; lutenizing hormone (LH), $36 \mathrm{U} / 1$ (N:1.5-8); estradiol, <10 pg/ml (N:20-85 in the follicular phase); anti-mullerian hormone, $<0.05 \mathrm{ng} / \mathrm{ml}$ (N:2,2-6.8) and inhibin B, <10 pg/ml (N:10-276). Androgen levels (testosterone, androstenedione and DHEA-S) were within the normal range (Table I). Ovarian ultrasonography at the age of 31 revealed two hypotrophic ovaries without follicles. No further evaluation was performed since the patient did not return to our center. Exploration of her deafness in another reference center excluded a mutation of $\mathrm{Cx} 26$.

\section{Functional studies of WT and mutated connexons}

Reduced gap-junction functionality in cells expressing the Gly316Ser Cx37variant. A Gap-FRAP analysis was performed on connexin-free HeLa cells (18), which were loaded with calcein-AM and photobleached. The fluorescence recovery was then monitored for $30 \mathrm{~min}$ (Fig. 2A). Fluorescence 
A
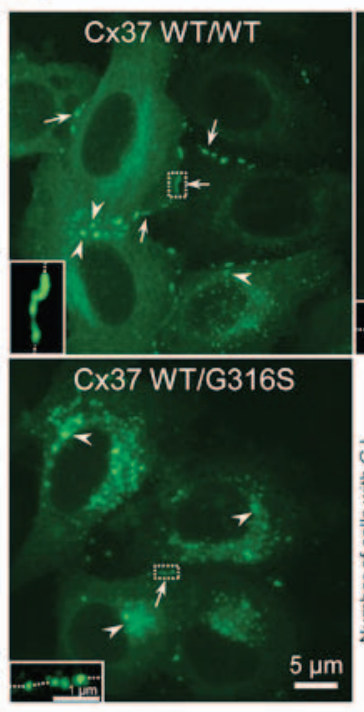
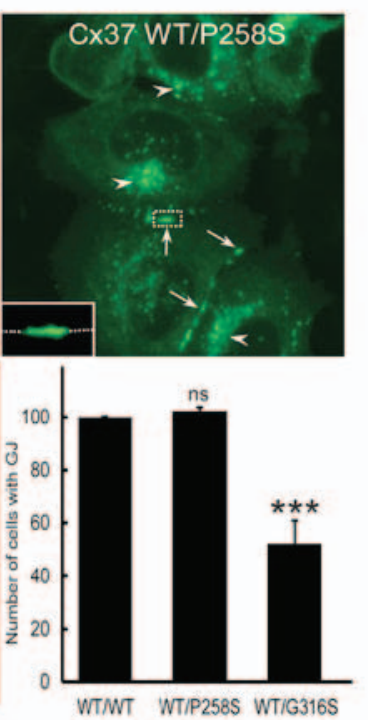

B

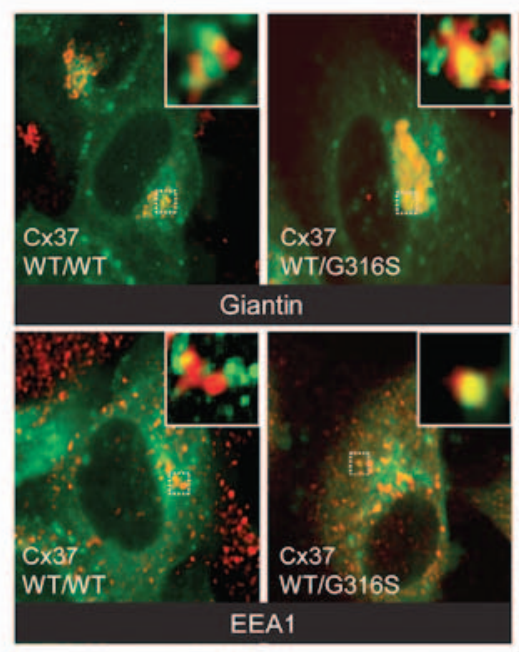

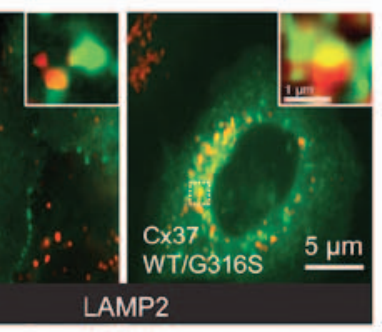

-

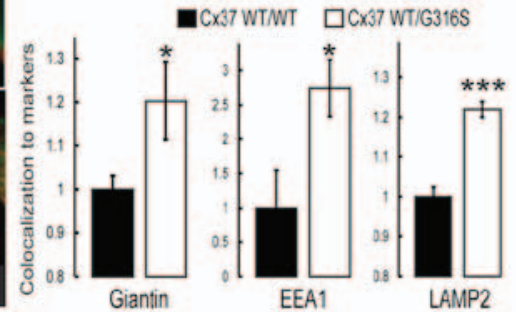

Figure 3. The Cx37-G316S variant markedly decreases the number of gap junction plaques by decreasing Cx37 exocytosis and increasing Cx37 endocytosis and degradation. (A) Representative images of HeLa cells transfected with GFP-Cx37-WT alone or together with GFP-Cx37-P258S or GFP-Cx37-G316S expression vectors. The number of gap junction plaques (arrows) was significantly lower in cells expressing GFP-Cx37-G316S, which also contained a larger number of cytoplasmic vesicles (arrowheads) (scale bar, $5 \mu \mathrm{m}$ ). For each images, a higher magnification was provided as inset and localized by dash-line squares to visualized more easily gap junction plaques at the cell-cell contacts (represented by dash-line in the insets). (B) Representative images of HeLa cells transfected with GFPCx37-WT alone or together with GFP-Cx37-G316S (green) and labeled (red) for giantin (Golgi marker), EEA1 (early endosomes) or LAMP2 (lysosomes). For each image, a higher magnification of $2 \times 2 \mu \mathrm{m}$ was provided as insets and localized by dash-line squares to visualized more easily co-localization (yellow color). The bottom right panel displays the quantification of $\mathrm{Cx} 37$ colocalization with the various markers used. * $\mathrm{P}<0.05$ and ${ }^{* * * *} \mathrm{P}<0.01$. ns, not significant; $\mathrm{Cx}$, connexin; GJ, gap junction; WT, wild-type; GFP, green fluorescence protein; EEA1, early endosome antigen 1; LAMP2, lysosome-associated membrane protein 2.

recovery was almost undetectable when a GFP-Rab5 expression vector was used as a negative control (Fig. 2B, left panel) $(n=3)$. First, the effect of the P258S variant was assessed. GJIC functionality in cells expressing only Cx37-WT did not differ significantly from that in cells co-expressing Cx37-WT and Cx37-P258S ( $\mathrm{P}=0.2617$; $=3$ ) (Fig. 2A, top and middle panels and Fig. 2B, left panel). This value was significantly higher than that of control cells transfected with GFP-Rab5 (with a 20-fold increase; $\mathrm{P}=0.0001 ; \mathrm{n}=3$ ) (Fig. 2B). The G316S variant, which was identified in certain Caucasian POI patients but absent in the controls of the present study and in Caucasian populations of databases was then studied. In contrast to the observation for the P258S variant, the G316S variant was less functional in vitro. The functionality of GJIC was $\sim 67.2 \pm 7.17 \%$ lower $(\mathrm{P}=0.0005, \mathrm{n}=5)$ when cells were co-transfected with Cx37-WT and Cx37-G316S (50:50) expression vectors (Fig. 2A, bottom and Fig. 2B, left panel). The use of smaller amounts of Cx37-G316S vector (75:25) rescued GJIC functionality (only $\sim 30.9 \pm 7.89 \%$ lower; $\mathrm{P}=0.0542$; $\mathrm{n}=3$ ) (Fig. 2B, right panel). Increasing the ratio of Cx37-G316S to Cx37-WT (25:75 or $0 / 100)$ did not further decrease GJIC functionality [56.7 $\pm 7.77 \%(\mathrm{P}=0.0076 ; \mathrm{n}=3)$ and $62.1 \pm 4.62 \%(\mathrm{P}=0.0029$; $\mathrm{n}=3$ ), respectively]. It was therefore concluded that the G316S variant has a partial dominant-negative effect on WT Cx37 in vitro.

Decreased expression of cell surface-associated gap junctions in cells expressing the G316S-Cx37 variant. The presence of cell-surface gap junction plaque was then assessed (Fig. 3A, arrows). As expected, no difference was identified between cells transfected with GFP-Cx37-WT and GFP-Cx37-P258S expression vectors $(\mathrm{P}=0.204 ; \mathrm{n}=3)$ (Fig. 3A). By contrast, much weaker expression was observed in cells co-expressing GFP-Cx37-WT and GFP-Cx37-G316S (47.73 $\pm 8.59 \%$; $\mathrm{P}=0.0052 ; \mathrm{n}=3$ ) (Fig. 3A). Furthermore, more connexin-loaded large vesicles accumulated within cells transfected with the G316S variant (Fig. 3A, arrowheads). It was concluded that the G316S variant, but not the P258S variant, decrease cellsurface gap junction plaque expression.

Altered trafficking of mutated G316S connexons in HeLa cells. Co-localization experiments with intracellular markers of Cx37-WT homomeric or Cx37-WT/Cx37-G316S heteromeric connexons were then performed. Co-localization with Giantin (a Golgi compartment marker) was significantly increased by the variant Cx37-G316S, by 20.2 $\pm 8.9 \%(P=0.0369$; $n=6$ ) (Fig. 3B, top left and bottom right panels), whereas that with EEA1, a specific endosomal marker, was markedly increased, by 174.5 $\pm 41.6 \%(P=0.0295 ; n=6)$ (Fig. 3B, bottom left and right panels), and that with LAMP2, a specific lysosomal marker, was increased by $21.9 \pm 1.98 \%(\mathrm{P}=0.0001 ; \mathrm{n}=6)$ (Fig. 3B, top right and bottom right panels). The $\mathrm{G} 316 \mathrm{~S}-\mathrm{Cx} 37$ variant thus appeared to decrease gap junction plaque formation at the cell surface, probably by increasing gap junction plaque endocytosis and lysosomal degradation. By contrast, no deleterious functional effect was detected with the P258S variant.

\section{Discussion}

The present study reported on an association between a single Cx37 variant and POI in two of 58 Caucasian patients from our national cohort (3), which was absent in the Caucasian control population, corresponding to two of the 58 patients with POI and 46 patients with secondary amenorrhea. 
A search of various databases indicated that the G316S mutation has not been reported in European or Caucasian North and South American, Caribbean and Asian populations. However, it has been reported in African populations according to the 1000G and ESV databases, strongly suggesting an ethnicityspecific interaction with environmental and/or genetic factors. In the ExAC database, in which a large number of chromosomes have been included, the G316S variant is rare in Caucasian populations, with $9 / 72,500$ alleles $(0.01241 \%)$ vs. $285 / 10,196$ alleles $(2.795 \%)$ detected in African populations. However, ExAC is unable to provide any information on the gender and the clinical status of variant carriers and it cannot be excluded that Caucasian female carriers are affected or will develop POI prior to the age of 40 years. However, it is unlikely that this variant is responsible for POI in African populations. Ethnicityspecific effects on genetic variants have been previously described (19-21). An important number of autosomal dominant disorders are characterized by incomplete penetrance (22), which may occur in specific populations. The asymptomatic state appears to be more common than the clinically overt state in several dominant disorders of haemostasis and thrombosis. Reduced penetrance in dominantly inherited diseases is likely to be the consequence of a combination of different genetic and environmental factors, which may vary among ethnic groups. Additional coding or non-coding variants acting in cis or trans may influence the expression of a potentially pathogenic allele or modulate its pathogenicity. In the genetic background of the patients of the present study, changes in conformation due to folding motif disruption or in protein-protein interactions critical for Cx37 trafficking may lead to protein retention within the cell and impaired GJIC function (23). In certain autosomal dominant conditions, the two alleles of a diseaseassociated gene are not expressed at the same level. This phenomenon drives a stronger expression of either the mutant or the WT allele, which may influence the clinical penetrance of the disorder. This is the case for retinis pigmentosa type 11, erythropoietic protoporphyria or Hirschsprung disease, in which penetrance depends not only on the nature of the mutation but also on the allele gene dosage (22). Modifier genes may also influence disease penetrance. The possibility that another mutation in an unknown gene is necessary for the expression of the phenotype in the Caucasian patients in a digenic mode of inheritance (24) or conversely that the African populations are protected by a common allele cannot be ruled out. A positive selection of the p.G316S variant in African populations may have also occurred, as this has been reported for the genes encoding globins, or in the case of glucose-6-phosphate dehydrogenase deficiency, leading to hematologic disorders when homozygous (sickle cell anemia or thalassemia) but protecting from malaria in a heterozygous state (25). An extreme case of positive selection across a wider evolutionary span has been reported for BMP15. Indeed, the substitution Y235C, which was the first mutation identified to be associated with POI (26), has invaded entire species and has been fixed as the WT allele in the hominids Pan troglodites and Pan paniscus (27). Obviously, the genetic background of these hominids has compensated any potential deleterious effects. Although not demonstrated in the present study, a similar compensatory effect may be present in African populations, which may not be unlikely given their higher genetic diversity and extensive population substructure compared with those of non-African populations. Africans also possess a number of genetic adaptations that have evolved in response to diverse climates and diets, as well as exposure to infectious disease (28). Recent genome-wide association studies on large populations have strongly associated a non-synonymous single nucleotide popymorphism in the minichromosome maintenance 8 homologous recombination repair factor (MCM8) gene involved in DNA repair with the age of menopause in Caucasian populations (29), but not in African populations (30). As mutations of MCM8 are responsible for POI (31), it is likely that the variant associated with the age of menopause in Caucasian populations is functional in those populations but not in African populations. It is also possible that Africans may have another mechanism to compensate the function of the MCM8 variant.

Several results provide additional support for the possible involvement of this $\mathrm{G} 316 \mathrm{~S}$ variant in disease pathogenesis in the Caucasian patients of the present study: i) The strong evolutionary conservation of the mutated residue supporting an important functional role; ii) the demonstrated functional consequences of the Cx37-G316S variant in vitro, while the P258S polymorphism present in different ethnic populations does not have any functional effect; and iii) the correlation between the phenotype of the patients with secondary amenorrhea and the partial dominant-negative effect of this heterozygous variant on the WT allele. Most of the connexin mutations implicated in human disease are dominant-negative (32).

Cx37-deficient mice are infertile $(14,15)$ due to arrested preantral follicle development. A study on mice with chimeric ovaries containing null mutant cells have indicated that GJIC between granulosa cells involves $\mathrm{Cx} 43$, whereas GJIC between oocytes and granulosa cells is constituted by $\mathrm{Cx} 37$ heterotypic channels (33).

The patients of the present study harbouring the Gly316Ser variant had a less severe ovarian phenotype than GJA4-knockout mice, as case 1 exhibited antral follicle development and estrogen secretion and case 2 presented with secondary amenorrhea. Indeed, the G316S variant has a partial dominant-negative effect on the WT Cx37 in vitro. The Cx37-G316S variant greatly decreased the number of gap junctions at the cell surface (by $47.73 \pm 8.59 \%$ ) and gap junction functionality (by $67.2 \pm 7.17 \%$ ). However, this difference was not statistically significant $(\mathrm{P}=0.0838)$, indicating that poorer functionality resulted mostly from changes in the gap junction number at the cell-cell boundary. The G316 variant affects the $\mathrm{Cx} 37 \mathrm{COOH}$-terminal domain, which is important for protein-protein interactions and trafficking $(23,34)$. Connexin trafficking is regulated by phosphorylation (34). The Ser316 residue was predicted to be phosphorylated (NetPhos 2.0 freeware; Technical University of Denmark, Kongens Lyngby, Denmark). This variant may therefore affect Cx37 trafficking and/or gap junction stabilization at the cell surface.

In mice with streptozotocin-induced diabetes, follicle maturation is delayed, with cumulus oocyte complex expansion failure and anovulation or dysovulation $(35,36)$. A $60 \%$ decrease in GJIC and a 36\% decrease in Cx37 protein levels (35) have been observed in this model, close to the values determined by the present study for the Cx37-G316S variant in vitro. These mice are subfertile, rather than infertile, with low-frequency 
ovulation, and even rare pregnancies. This phenotype is similar to that presented by case 1 of the present study, with resumption of ovarian function. Case 2 developed a secondary ovarian insufficiency, but the possibility of an additional genetic defect cannot be excluded. The latter may have impacted the phenotypic expression of the GJA4 mutation. Alternatively, variable phenotypic expression of a single molecular defect has been frequently documented in human reproductive disorders. Indeed, intra- and inter-familiar phenotypic variability has been documented for the same forkhead box L2 mutation, inducing blepharophymosis syndrome type 1 (associated with ovarian failure) occurring twice in the same family. This may reflect the combination of the effect of modifier genes or of a different genetic background, and possibly of the environment (37).

The resumption of ovarian function in the presence of constantly high gonadotropin concentrations in case 1 suggests a compensatory role of gonadotropins. $\mathrm{FSH}$ and $\mathrm{LH}$ regulate follicular development and oocyte maturation, and high LH levels may contribute to meiosis resumption $(38,39)$. Connexin phosphorylation may also be physiologically enhanced by gonadotropins $(13,38)$. FSH increases Cx43 synthesis and plasma membrane translocation $(40,41)$. Similarly, FSH may also increase $\mathrm{Cx} 37$ synthesis and connexon targeting to the cell surface up to the threshold required for complete follicular function. Cx43 has been demonstrated to be present in human cumulus cells in vitro and may form heterotypic connexons with $\mathrm{Cx} 37$ in the oocyte (42). Cx43 has been demonstrated to compensate for defective $\mathrm{Cx} 37$ function (43). An analogous compensatory effect of an FSH-induced Cx43 increase cannot be excluded in the patients of the present study. Cx37 appears to be indispensable for complete oocyte growth and meiotic competence in mice (15). Oocytes from Cx37-deficient mice cannot enter the $\mathrm{M}$ phase (initial meiotic maturation) (15). However, the G316S mutation in the patients of the present study led to the partial trapping of certain G316S connexons within the cell, whereas the rest was targeted to the cell surface and was demonstrated to be functional in vitro. Partial oocyte maturation may thus be possible and this, together with prolonged high gonadotropin concentrations in the blood, may lead to the coordinate completion of follicular and oocyte maturation and resumption of ovarian function in certain patients.

The present study demonstrated an association between a Cx37 variant absent in Caucasian populations but present in 2 Caucasian POI patients, displaying a dominant-negative effect in vitro. These results suggested that in the genetic context of the Caucasian population, this variant may contribute to the POI phenotype in vivo. Exome studies may be performed in the future to identify further causative mutations associated with the development of POI in the patients of the present study. Further experiments in physiologically relevant models are required to incriminate this $\mathrm{Cx} 37$ variant as having a causative role in the pathology of POI alone or in association with another causative genes, as observed in other reproductive diseases (24).

\section{Acknowledgements}

The authors would like to thank Dr Georges Pointis (INSERM U1065, F-06000 Nice, France) and Dr Emmanuel Génin (INSERM U1078, Brest, France) for their helpful discussions, as well as Dominique Segretain (Paris Descartes University, 75005 Paris, France) and Laurent Combettes (INSERM U757, 91400 Orsay, France) for their helpful discussions and for providing access to their laboratory facilities and materials.

\section{References}

1. European Society for Human Reproduction and Embryology (ESHRE) Guideline Group on POI, Webber L, Davies M, Anderson R, Bartlett J, Braat D, Cartwright B, Cifkova R, de Muinck Keizer-Schrama S, Hogervorst E, Janse F, et al: ESHRE Guideline: management of women with premature ovarian insufficiency. Hum Reprod 31: 926-937, 2016.

2. Nelson LM: Clinical practice. Primary ovarian insufficiency. N Engl J Med 360: 606-614, 2009.

3. Bachelot A, Rouxel A, Massin N, Dulon J, Courtillot C, Matuchansky C, Badachi Y, Fortin A, Paniel B, Lecuru F, et al; POF-GIS Study Group: Phenotyping and genetic studies of 357 consecutive patients presenting with premature ovarian failure. Eur J Endocrinol 161: 179-187, 2009.

4. Beau I, Touraine P, Meduri G, Gougeon A, Desroches A, Matuchansky C, Milgrom E, Kuttenn F and Misrahi M: A novel phenotype related to partial loss of function mutations of the follicle stimulating hormone receptor. J Clin Invest 102: 1352-1359, 1998

5. Bidet M, Bachelot A, Bissauge E, Golmard JL, Gricourt S, Dulon J, Coussieu C, Badachi Y and Touraine P: Resumption of ovarian function and pregnancies in 358 patients with premature ovarian failure. J Clin Endocrinol Metab 96: 3864-3872, 2011.

6. Tucker EJ, Grover SR, Bachelot A, Touraine P and Sinclair AH: Premature ovarian insufficiency: New perspectives on genetic cause and phenotypic spectrum. Endocr Rev 37: 609-635, 2016.

7. Meduri G, Bachelot A, Cocca MP, Vasseur C, Rodien P, Kuttenn F, Touraine P and Misrahi M: Molecular pathology of the FSH receptor: New insights into FSH physiology. Mol Cell Endocrinol 282: 130-142, 2008.

8. Wang J, Zhang W, Jiang $\mathrm{H}$ and $\mathrm{Wu}$ BL; Primary Ovarian Insufficiency Collaboration: Mutations in HFM1 in recessive primary ovarian insufficiency. N Engl J Med 370: 972-974, 2014.

9. Caburet S, Arboleda VA, Llano E, Overbeek PA, Barbero JL, Oka K, Harrison W, Vaiman D, Ben-Neriah Z, García-Tuñón I, et al: Mutant cohesin in premature ovarian failure. $\mathrm{N}$ Engl J Med 370: 943-949, 2014.

10. Bouilly J, Bachelot A, Broutin I, Touraine P and Binart N: Novel NOBOX loss-of-function mutations account for $6.2 \%$ of cases in a large primary ovarian insufficiency cohort. Hum Mutat 32: 1108-1113,2011.

11. Wood-Trageser MA, Gurbuz F, Yatsenko SA, Jeffries EP, Kotan LD, Surti U, Ketterer DM, Matic J, Chipkin J, Jiang H, et al: MCM9 mutations are associated with ovarian failure, short stature, and chromosomal instability. Am J Hum Genet 95: 754-762, 2014.

12. AlAsiri S, Basit S, Wood-Trageser MA, Yatsenko SA, Jeffries EP, Surti U, Ketterer DM, Afzal S, Ramzan K, Faiyaz-Ul Haque M, et al: Exome sequencing reveals MCM8 mutation underlies ovarian failure and chromosomal instability. J Clin Invest 125: 258-262, 2015.

13. Gershon E, Plaks V and Dekel N: Gap junctions in the ovary: Expression, localization and function. Mol Cell Endocrinol 282: 18-25, 2008.

14. Simon AM, Goodenough DA, Li E and Paul DL: Female infertility in mice lacking connexin 37. Nature 385: 525-529, 1997.

15. Carabatsos MJ, Sellitto C, Goodenough DA and Albertini DF: Oocyte-granulosa cell heterologous gap junctions are required for the coordination of nuclear and cytoplasmic meiotic competence. Dev Biol 226: 167-179, 2000.

16. Gilleron J, Fiorini C, Carette D, Avondet C, Falk MM, Segretain D and Pointis G: Molecular reorganization of Cx43, Zo-1 and Src complexes during the endocytosis of gap junction plaques in response to a non-genomic carcinogen. J Cell Sci 121: 4069-4078, 2008.

17. Gilleron J, Carette D, Fiorini C, Dompierre J, Macia E, Denizot JP, Segretain D and Pointis G: The large GTPase dynamin2: A new player in connexin 43 gap junction endocytosis, recycling and degradation. Int J Biochem Cell Biol 43: 1208-1217, 2011.

18. Carette D, Gilleron J, Decrouy X, Fiorini C, Diry M, Segretain D and Pointis G: Connexin 33 impairs gap junction functionality by accelerating connexin 43 gap junction plaque endocytosis. Traffic 10: 1272-1285, 2009. 
19. Tishkoff SA and Williams SM: Genetic analysis of African populations: Human evolution and complex disease. Nat Rev Genet 3: 611-621, 2002.

20. Bentley-Lewis R, Powe C, Ankers E, Wenger J, Ecker J and Thadhani R: Effect of race/ethnicity on hypertension risk subsequent to gestational diabetes mellitus. Am J Cardiol 113: 1364-1370, 2014

21. Jing L, Su L and Ring BZ: Ethnic background and genetic variation in the evaluation of cancer risk: A systematic review. PLoS One 9: e97522, 2014.

22. Cooper DN, Krawczak M, Polychronakos C, Tyler-Smith C and Kehrer-Sawatzki H: Where genotype is not predictive of phenotype: Towards an understanding of the molecular basis of reduced penetrance in human inherited disease. Hum Genet 132: 1077-1130, 2013.

23. Hervé JC, Derangeon M, Sarrouilhe D, Giepmans BN and Bourmeyster N: Gap junctional channels are parts of multiprotein complexes. Biochim Biophys Acta 1818: 1844-1865, 2012.

24. Pitteloud N, Durrani S, Raivio T and Sykiotis GP: Complex genetics in idiopathic hypogonadotropic hypogonadism. Front Horm Res 39: 142-153, 2010.

25. Kwiatkowski DP: How malaria has affected the human genome and what human genetics can teach us about malaria. Am J Hum Genet 77: 171-192, 2005.

26. Di Pasquale E, Beck-Peccoz P and Persani L: Hypergonadotropic ovarian failure associated with an inherited mutation of human bone morphogenetic protein-15 (BMP15) gene. Am J Hum Genet 75: 106-111, 2004.

27. Auclair S, Rossetti R, Meslin C, Monestier O, Di Pasquale E, Pascal G, Persani L and Fabre S: Positive selection in bone morphogenetic protein 15 targets a natural mutation associated with primary ovarian insufficiency in human. PLoS One 8: e78199, 2013.

28. Campbell MC and Tishkoff SA: African genetic diversity: Implications for human demographic history, modern human origins, and complex disease mapping. Annu Rev Genomics Hum Genet 9: 403-433, 2008.

29. Chen CT, Liu CT, Chen GK, Andrews JS, Arnold AM, Dreyfus J, Franceschini N, Garcia ME, Kerr KF, Li G, et al: Meta-analysis of loci associated with age at natural menopause in AfricanAmerican women. Hum Mol Genet 23: 3327-3342, 2014.

30. Spencer KL, Malinowski J, Carty CL, Franceschini N, FernándezRhodes L, Young A, Cheng I, Ritchie MD, Haiman CA, Wilkens L, et al: Genetic variation and reproductive timing: African American women from the Population Architecture using Genomics and Epidemiology (PAGE) Study. PLoS One 8: e55258, 2013.

31. Yatsenko SA and Rajkovic A: Reproductive aging and MCM8/9. Oncotarget 6: 15750-15751, 2015.

32. Pando MJ, Gardiner CM, Gleimer M, McQueen KL and Parham P: The protein made from a common allele of KIR3DL1 $(3 \mathrm{DL} 1 * 004)$ is poorly expressed at cell surfaces due to substitution at positions 86 in Ig domain 0 and 182 in Ig domain 1. J Immunol 171: 6640-6649, 2003.
33. Gittens JE and Kidder GM: Differential contributions of connexin37 and connexin43 to oogenesis revealed in chimeric reaggregated mouse ovaries. J Cell Sci 118: 5071-5078, 2005.

34. Johnson KE, Mitra S, Katoch P, Kelsey LS, Johnson KR and Mehta PP: Phosphorylation on Ser-279 and Ser-282 of connexin43 regulates endocytosis and gap junction assembly in pancreatic cancer cells. Mol Biol Cell 24: 715-733, 2013.

35. Chang AS, Dale AN and Moley KH: Maternal diabetes adversely affects preovulatory oocyte maturation, development, and granulosa cell apoptosis. Endocrinology 146: 2445-2453, 2005.

36. Ratchford AM, Esguerra CR and Moley KH: Decreased oocytegranulosa cell gap junction communication and connexin expression in a type 1 diabetic mouse model. Mol Endocrinol 22: 2643-2654, 2008.

37. De Baere E, Beysen D, Oley C, Lorenz B, Cocquet J, De Sutter P, Devriendt K, Dixon M, Fellous M, Fryns JP, et al: FOXL2 and BPES: Mutational hotspots, phenotypic variability, and revision of the genotype-phenotype correlation. Am J Hum Genet 72: 478-487, 2003.

38. Norris RP, Freudzon M, Mehlmann LM, Cowan AE, Simon AM, Paul DL, Lampe PD and Jaffe LA: Luteinizing hormone causes MAP kinase-dependent phosphorylation and closure of connexin 43 gap junctions in mouse ovarian follicles: One of two paths to meiotic resumption. Development 135: 3229-3238, 2008.

39. Zhang M, Ouyang H and Xia G: The signal pathway of gonadotrophins-induced mammalian oocyte meiotic resumption. Mol Hum Reprod 15: 399-409, 2009.

40. Wang HX, Gillio-Meina C, Chen S, Gong XQ, Li TY, Bai D and Kidder GM: The canonical WNT2 pathway and FSH interact to regulate gap junction assembly in mouse granulosa cells. Biol Reprod 89: 39, 2013.

41. Gilleron J, Carette D, Carpentier F, Segretain D and Pointis G: Three-dimensional analysis of connexin 43 gap junction in the ex vivo rat seminiferous tubules: Short-term effects of hormonal effectors. Microsc Res Tech 72: 845-855, 2009.

42. Wang HX, Tong D, El-Gehani F, Tekpetey FR and Kidder GM: Connexin expression and gap junctional coupling in human cumulus cells: Contribution to embryo quality. J Cell Mol Med 13: 972-984, 2009.

43. Li TY, Colley D, Barr KJ, Yee SP and Kidder GM: Rescue of oogenesis in Cx37-null mutant mice by oocyte-specific replacement with Cx43. J Cell Sci 120: 4117-4125, 2007.

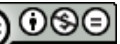

This work is licensed under a Creative Commons Attribution-NonCommercial-NoDerivatives 4.0 International (CC BY-NC-ND 4.0) License. 